\title{
A Nonlinear Dynamic System In Behavioral Finance: Evidence From Chinese Stock Market
}

\author{
Jun XIE \\ College of Mathematics and Information Science, Guangxi University, \\ Guangxi, China \\ E-mail: gxaone@163.com
}

\begin{abstract}
This paper uses linear and nonlinear Granger causality tests to examine a dynamic behavioral finance system which composed by the stock index price, investor sentiment and the willingness to investment. We find that the linear dynamic system is simple and unidirectional, but nonlinear dynamic system is complex and bidirectional. And we can predict the index return more accurately by using the nonlinear dynamic system, because the linear dynamic system may lose some variables which have nonlinear effects on the index return.
\end{abstract}

Keywords-Investor sentiment; Willingness to investment; Non-linear Granger causality; Behavioral finance

\section{INTRODUCTION}

How do investors predict the assets (index) prices or returns? What are the factors that influence investors' prediction? Conventional financial analysis (e.g. Fame and French, 1995) often fails to give an accurate prediction for the assets prices or returns due to inherent irrational patterns and nonlinear components. Approvers of the behavioral finance try to take corrective actions. There are convincing evidences in literatures on behavioral finance that discuss the psychological factors (see e.g. Shefrin, 2000; Shiller, 2000; Statman, 2014), and some literatures analyze the nonlinear relationship between some two variables (see e.g. Rashid, 2007; Dergiades, 2014).

Lots of psychological factors can be considered as the effect of investor sentiment, such as: Familiarity and loyalty considered as the effect of optimistic sentiment; Ambiguity aversion considered as the effect of pessimistic sentiment. And an increasing number of empirical papers devote to the researches of investor sentiment, such as: Baker and Wurgler (2007), Han (2008), Chi, et al. (2012) and Stambaugh et al. (2014). Therefore, in steading of psychological factors, we discuss the effect of investor sentiment on the process of prediction. In contrast to existing literatures, we analyze the willingness to investment at once in the paper. In other words, we examine the interactive relationships among the index price or return, investor sentiment and the willingness to investment in the paper, and these three factors construct a behavioral finance system. In this system, we just try to give more accurate prediction of the index price or return.

A common feature of the existing studies which discuss the prediction of the asset (index) prices or return is that the causality adheres to the linear causality paradigm (see Brown and Cliff, 2004; Lux, 2011). But economic data are not generally described by simple linear structural models (Bekiros, 2013). Thus, Rashid (2007) investigated the dynamic association between daily stock index returns and percentage trading volume changes by using linear and nonlinear Granger causality tests. Dergiades (2014) discussed the nonlinear causality between investor sentiment and stock returns by using US economic data.

This paper extends the above studies to a behavioral finance system which composed of three variables: the index price or return, investor sentiment and the willingness to investment. We not only discuss the predication performance for the index price or return based on the willingness to investment and investor sentiment, but also consider the bidirectional relationship among the three variables. For the market participants, what we do may enhance predictability with respect to the conditional mean and contribute towards the realization of excess returns. For researchers, what we do may supplement nonlinear theoretical mechanisms and empirical regularities of the behavioral finance system.

The remainder of this paper proceeds as follows: Section 2 presents the data sources and the methodology, Section 3 presents the results of the linear and nonlinear Granger causality tests, Section 4 concludes.

\section{DATA AND METHODOLOGY}

\section{A. Data Sources}

We employ quarterly time-series data for the Chinese economy over the period 2003: Q2 to 2004: Q2. The Chinese stock price index is represented by Shanghai index, with the index return to be computed as the quarterly percentage change. The index of willingness to investment is obtained from urban depositor survey which arranged by People's Bank of China (Statistics and Analysis Department). The survey is told to make a choice among "more spending", "more saving" and "more investing" within 3 months from now. The percentage of "more investing" is used as the index of willingness to investment.

The Chinese investor sentiment index is computed through the method of Baker and Wurgler (2007). Because some variables those used by Baker and Wurgler are unavailable in China, we use amplitude of Shanghai index (Am), turnover 
rate weighted by circulated market value (TR), new stock accounts (NS), advance/decline ratio (AD R) and closing price of fund index in Shanghai (CP) as the proxy variables to achieve Chinese investor sentiment index. By the principal component analysis, we find that the Chinese investor sentiment index (S) can be given by the following formula:

$$
S=0.42 \cdot A M+0.54 \cdot T R+0.56 \cdot N S+0.41 \cdot A D R+0.26 \cdot C P
$$

Except for the index of willingness to investment, all timeseries data used in this paper are obtained from CSMAR.

\section{B. Methodology}

We study an economic system which is composed of willingness to investment (W), investor sentiment (S) and the stock index price $(\mathrm{P})$. To examine whether the dynamic system is linear or nonlinear, we use linear Granger-Causality Wald tests and non-linear Granger-Causality tests. Because causality tests are sensitive to non-stationarity, we should study the strict stationarities of the variables. If the variables are nonstationary, we may use the change of willingness to investment $(\mathrm{CW})$, the change of investor sentiment $(\mathrm{CS})$ and the stock index return $(\mathrm{R})$ to replace the above three variables.

Granger-Causality tests (Granger, 1969) has been widely used in the study of finance. For two scalar-valued, stationary, and ergodic time series $\left\{X_{t}\right\}$ and $\left\{\mathrm{Y}_{t}\right\}$, let $I_{X, t}$ and $I_{\mathrm{Y}, t}$ be respectively the information set consisting of t-length lagged information of $X_{t}$ and $Y_{t}$. The time series $\left\{X_{t}\right\}$ does not strictly Granger cause $\left\{\mathrm{Y}_{t}\right\}$ if:

$$
\left(\mathrm{Y}_{t+1}, \cdots, Y_{t+k}\right)\left|\left(I_{X, t}, I_{Y, t}\right) \sqcap\left(\mathrm{Y}_{t+1}, \cdots, Y_{t+k}\right)\right| I_{Y, t} .
$$

However, with the development of nonlinear theory of finance, many nonlinear features have been discovered. While, linear Granger-Causality tests have low power detecting certain kinds of nonlinear causal relations. Diks and Panchenko (2006) propose a nonparametric statistical method (nonlinear Granger-Causality tests) for uncovering nonlinear causal relations. Next, we describe the fundamental principles of nonlinear Granger-Causality tests.

Let $\mathbf{X}_{t}^{l x}$ be the $l x$-length lead vector of $X_{t}$, that is $\mathbf{X}_{t}^{l x}=\left(X_{t-l x+1}, \cdots, X_{t}\right)$ and $\mathbf{Y}_{t}^{l y}$ be the $l y$-length lead vector of $Y_{t}$ that is $\mathbf{Y}_{t}^{l y}=\left(Y_{t-l y+1}, \cdots, Y_{t}\right)$. The null hypothesis is given by no causality. In other words,

$$
H_{0}: Y_{t+1}\left|\left(\mathbf{X}_{t}^{l x} ; \mathbf{Y}_{t}^{l y}\right) \square Y_{t+1}\right| \mathbf{Y}_{t}^{l y}
$$

Note $W_{t}=\left(\mathbf{X}_{t}^{l x}, \mathbf{Y}_{t}^{l y}, Z_{t}\right)$, where $Z_{t}=Y_{t+1}$. For presentation purpose, $l x=l y=1$ is set. Under the null hypothesis, eq. (1) implies that the joint probability density function $f_{X, Y, Z}(\mathrm{x}, \mathrm{y}, \mathrm{z})$ along with its margin, should satisfy:

$$
\frac{f_{X, Y, Z}(x, y, z)}{f_{Y}(y)}=\frac{f_{X, Y}(\mathrm{x}, \mathrm{y}) f_{\mathrm{Y}, \mathrm{Z}}(\mathrm{x}, \mathrm{y})}{f_{Y}(y) f_{Y}(y)} .
$$

Further research showed by Diks and Panchenko (2006) that eq. (2) can be restated as:

$$
q \equiv E\left[f_{X, Y, Z}(X, Y, Z) f_{Y}(\mathrm{Y})-f_{X, Y}(\mathrm{X}, \mathrm{Y}) f_{Y, Z}(Y, Z)\right]=0
$$

And denote as $\hat{f}_{\mathrm{W}}\left(W_{i}\right)$ the local density estimator of the vector $\mathbf{W}$ at $W_{i}$, that is:

$$
\hat{f}_{\mathbf{W}}\left(W_{i}\right)=\left(2 \theta_{n}\right)^{-d w}(\mathrm{n}-1)^{-1} \sum_{j, j \neq i} K_{i j}^{W}
$$

Where, $K_{i j}^{W}=K\left(\left\|W_{i}-W_{j}\right\|<\theta_{n}\right) \quad$ with $K(\cdot)$ to be the indicator function and $\theta_{n}$ the bandwidth which depends on the sample size. Then we can get the proposed estimator for $q$ as:

$$
\begin{aligned}
T_{n}\left(\theta_{n}\right)= & \frac{n-1}{n(\mathrm{n}-2)} \sum_{i}\left(\hat{f}_{X, Y, Z}\left(X_{i}, Y_{i}, Z_{i}\right) \hat{f}_{Y}\left(Y_{i}\right)\right. \\
& \left.-\hat{f}_{X, Y}\left(X_{i}, Y_{i}\right) \hat{f}_{Y, Z}\left(Y_{i}, Z_{i}\right)\right)
\end{aligned}
$$

It has been proved by Diks and Panchenko (2006) that $T_{n}\left(\theta_{n}\right)$ static converges to the standard normal distribution:

$$
\sqrt{n} \frac{\left(T_{n}\left(\theta_{n}\right)-q\right)}{S_{n}} \stackrel{D}{\longrightarrow} N(0,1)
$$

Where, $S_{n}$ is the estimated standard error of $T_{n}(\cdot)$.

\section{EMPIRICAL RESULTS}

In this section, we present the applications of the linear and nonlinear Granger-Causality tests to aggregate the willingness to investment, investor sentiment and the stock index price.

\section{A. Stationarity of the data}

TABLE I. UNIT ROOT AND STATIONARITY TESTS.

\begin{tabular}{lllllll}
\hline & \multicolumn{2}{c}{ ADF } & \multicolumn{2}{c}{ GLS-DF } & \multicolumn{2}{c}{ KPSS } \\
& No trend & Trend & $\begin{array}{l}\text { No } \\
\text { trend }\end{array}$ & Trend & $\begin{array}{l}\text { No } \\
\text { trend }\end{array}$ & Trend \\
P & -1.829 & -1.829 & -1.430 & -1.624 & 0.219 & $0.152^{* *}$ \\
R & $-3.897^{* * *}$ & $-4.029^{* *}$ & $-3.512^{* * *}$ & $-3.871^{* * *}$ & 0.115 & 0.061 \\
S & -2.447 & -2.407 & $-2.294^{* *}$ & -2.397 & 0.173 & $0.174^{* *}$ \\
CS & $-6.921^{* * *}$ & $-6.898^{* * *}$ & $-6.894^{* * *}$ & $-6.997^{* * *}$ & 0.088 & 0.051 \\
W & $-2.960^{* *}$ & -2.929 & $-2.882^{* * *}$ & $-2.982^{*}$ & 0.119 & 0.100 \\
CW & $-6.825^{* * *}$ & $-6.746^{* * *}$ & $-6.892^{* * *}$ & $-6.813^{* * *}$ & 0.084 & 0.077 \\
\hline
\end{tabular}

Notes: *, ** and *** denote rejection of the null hypothesis at the $10 \%, 5 \%$ and $1 \%$ nominal level, respectively. The lag-length (ADF and GLS-DF) selected is based on the AIC. The bandwidth for the KPSS test is chosen according to the Newel-West selection procedure (spectral method: Bartlett kernel).

Linear and nonlinear Granger-Causality tests both are sensitive to non-stationary. From the fig. 1 and fig. 2, we can 
easily find that the willingness to investment $(\mathrm{W})$, investor sentiment (S) and the stock index Price (P) all may be nonstationarity. To identify the exact integration order of the variables, we do the ADF test, the GLS-DF test and the KPSS test. The results of the unit root and stationarity tests are illustrated in Table 1.

Obviously, for the variables P, S and W, at least one of the tests shows that we can't reject that these variables have unit root. For the variables R, CS and CW, we reject the null hypothesis for ADF and GLS-DF tests, while the opposite holds for the KPSS test. Thus, we will analyze the dynamic system in behavioral finance by using variables R, CS and CW in the next subsection.

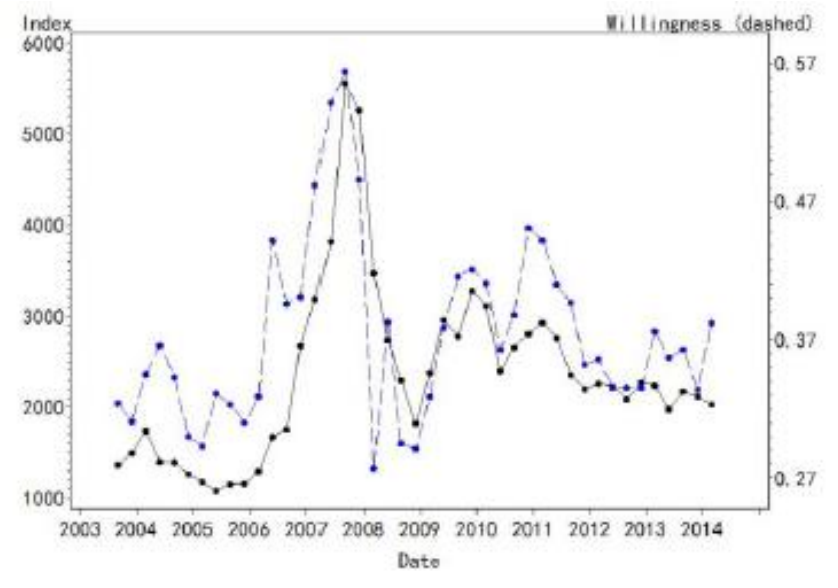

Figure 1. Shanghai index and willingness to investment.

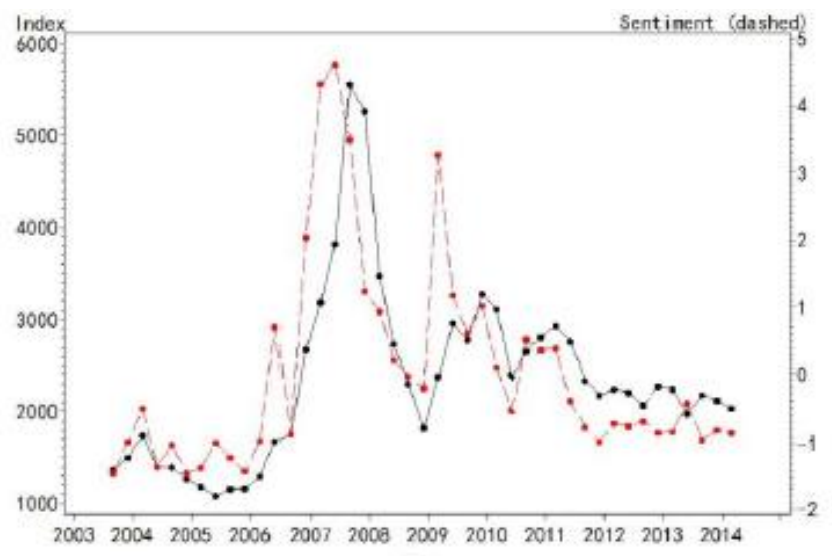

Figure 2. Shanghai index and investor sentiment.

\section{B. Linear Granger-Causality Test Results}

Traditional financial theories always assume that the financial system is a linear system. In this subsection, we test whether the linear feature is significant by using linear Granger-Causality Wald test.
TABLE II. LINEAR GRANGER-CAUSALITY WALD TESTS.

\begin{tabular}{lllll}
\hline \multicolumn{5}{c}{ The lag-length } \\
& 1 & 2 & 3 & 4 \\
R->CS & $2.49(0.11)$ & $6.57^{* *}(0.04)$ & $19.83^{* * *}(0.00)$ & $12.65^{* *}(0.01)$ \\
R->CW & $1.22(0.26)$ & $2.69(0.26)$ & $4.72(0.19)$ & $3.37(0.50)$ \\
CS->R & $1.81(0.18)$ & $1.57(0.46)$ & $2.08(0.56)$ & $5.19(0.27)$ \\
CS->CW & $0.66(0.42)$ & $1.62(0.45)$ & $3.50(0.32)$ & $9.04(0.06)$ \\
CW->R & $1.39(0.24)$ & $3.20(0.20)$ & $3.54(0.32)$ & $14.46^{* * *}(0.01)$ \\
CW->CS & $16.40^{* * *}(0.00)$ & $21.71^{* * *}(0.00)$ & $22.43^{* * *}(0.00)$ & $23.32^{* * *}(0.00)$ \\
\hline
\end{tabular}

Notes: *, ** and *** denote rejection of the null hypothesis at the $10 \%, 5 \%$ and $1 \%$ nominal level, respectively. The max lag-length is 4 , because the variables are quarterly time-series.

Table 2 reports the results of linear Granger-Causality Wald test. Focusing on rejections of the null hypothesis, we find that Granger non-causality from $\mathrm{CW}$ to $\mathrm{CS}$ can be rejected for all four lag-lengths, and Granger non-causality from R to CS can be rejected for 2-4 lag-lengths. However, for variable $\mathrm{R}$ which the investors are more focusing on, Granger non-causality only from the 4th lagged CW to R can

Be rejected. In other words, this linear dynamic system is simple and only 4th lagged "the change of willingness to investment" can be used to predict the index return (see Fig. 3).

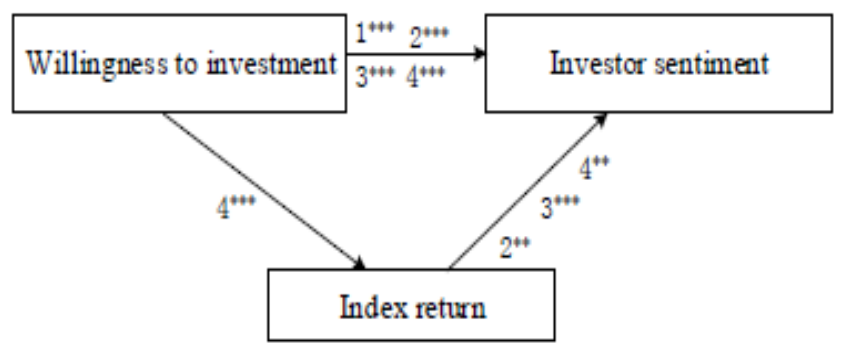

Figure 3. Linear dynamic system.

\section{Nonlinear Granger-Causality Test Results}

To implement the nonlinear Granger-Causality tests, each time series is standardized so that the two series share a common standard deviation, i.e., $\sigma=1$ and thereby share a common scale parameter.

TABLE III. NONLINEAR GRANGER-CAUSALITY TESTS.

\begin{tabular}{lclll}
\hline \multicolumn{5}{c}{ The lag-length $(l x=l y)$} \\
& 1 & 2 & 3 & 4 \\
& & & & \\
R->CS & $0.060^{* *}(0.0$ & $0.071^{* *}(0.04$ & $0.038^{* * *}(0.1$ & - \\
& $30)$ & $4)$ & $20)$ & $0.002^{* *}(0.54$ \\
R->C & $0.041^{* *}(0.0$ & $0.056^{*}$ & 0.051 & -0.011 \\
W & $14)$ & $(0.082)$ & $(0.185)$ & $(0.569)$ \\
CS->R & $0.073^{*}$ & $0.098^{* *}(0.04$ & $0.093^{* *}(0.01$ & $0.187^{* *}(0.0$ \\
CS->C & $(0.056)$ & $3)$ & $7)$ & $33)$ \\
W & -0.001 & 0.042 & 0.060 & 0.145 \\
CW-> & $(0.520)$ & $(0.106)$ & $(0.198)$ & $(0.060)$ \\
R & $0.048^{* *}(0.0$ & $0.127^{* * *}(0.0$ & $0.118^{* *}(0.01$ & $0.118^{* *}(0.0$ \\
CW-> & $36)$ & $08)$ & $3)$ & $41)$ \\
CS & $0.064^{* *}(0.0$ & $0.075^{*}$ & $0.062^{*}$ & 0.055 \\
& $31)$ & $(0.051)$ & $(0.057)$ & $(0.152)$ \\
\hline
\end{tabular}


Notes: *,** and *** denote rejection of the null hypothesis at the $10 \%, 5 \%$ and $1 \%$ nominal level, respectively.

Table 3 presents the results of the nonlinear GrangerCausality tests. Cleanly, significant bidirectional nonlinear causality running from $\mathrm{CS}$ to $\mathrm{R}$ and from $\mathrm{CW}$ to $\mathrm{R}$ are revealed. And there is a significant unidirectional causality running from $\mathrm{CW}$ to $\mathrm{CS}$. To facilitate discussions, we present these nonlinear dynamic relationships in the Fig. 4. Nonlinear Granger non-causality from CS to R and from CW to R all can be rejected for all four lag-lengths. On the other hand, we can't reject the nonlinear Granger non-causality from $\mathrm{CS}$ to $\mathrm{CW}$ for all four lag-lengths, but we can reject the nonlinear Granger non-causality from $\mathrm{CW}$ to $\mathrm{CS}$ for 1-3 lag-lengths at the 0.1 nominal level.

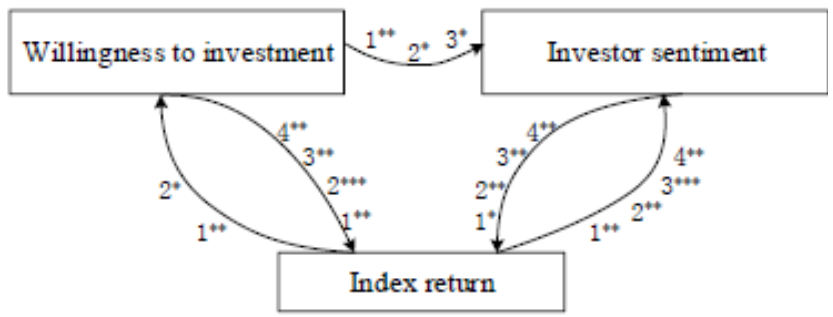

Figure 4. Nonlinear dynamic system.

These results imply that we can use "the change of willingness to investment" and "the change of investor sentiment" to predict the stock index return, but it may be complex because all lagged variables (1-4 lag-lengths) may have nonlinear effects on the index return. From another aspect, only the previous change of "willingness to investment" have the effects on the change of investor sentiment, while the previous change of investor sentiment has no effect on the change of willingness to investment. And investor sentiment may be affected by the previous index return and the previous willingness to investment. That is to say, this nonlinear dynamic system (see Fig. 4) is more complex than the linear dynamic system, the nonlinear dynamic system is bidirectional relationship. And maybe we can predict the index return more accurately by using the nonlinear dynamic system, because the linear system may lose some variables which have nonlinear effects on the index return.

\section{CONCLUSIONS}

This paper uses linear and nonlinear Granger causality tests to examine a dynamic behavioral finance system which composed by the index price (or return), investor sentiment and the willingness to investment. The linear Granger causality tests reveal that there are only significant unidirectional causality's from R to CS, from CW to CS and from $\mathrm{CW}$ to $\mathrm{R}$. And the nonlinear Granger causality tests demonstrate that there are significant bidirectional causality's between $\mathrm{R}$ and $\mathrm{CS}$ and between $\mathrm{R}$ and $\mathrm{CW}$, and there is significant unidirectional causality from $\mathrm{CW}$ to $\mathrm{CS}$. a) Comparing the two results of linear and nonlinear Granger causality tests, we prove that the linear dynamic system is a simple unidirectional system, but nonlinear dynamic system is a complex bidirectional system. In particularly, only 4th lagged CW can be used to predict the index return in the linear system, but we should use all four lagged CW and CS to predict the index return in the nonlinear system. It suggests that the market participants predicting the index return by using the linear system may lose lots of variables and may be difficult to achieve an accurate prediction, and researchers should consider nonlinear theoretical mechanisms and empirical regularities when studying behavioral finance system.

\section{ACKNOWLEDGMENT}

The authors gratefully acknowledge the support by the Guangxi Natural Science Foundation (2015GXNSFBA139015)

\section{REFERENCES}

[1] Baker, M., Wurgler, J., 2007. Investor sentiment in the stock market. Journal of Economic Perspectives, 21(2), 129-151.

[2] Bekiros, S. D., 2013. Irrational fads, short-term memory emulation, and asset predictability. Review of Financial Economics 22(4), 213219.

[3] Brown, G.W., Cliff, M.T., 2004. Investor sentiment and the near-term stock market. Journal of Empirical Finance 11 (1), 1-27.

[4] Chi, L., Zhuang, X., Song, D., 2012. Investor sentiment in the Chinese stock market: an empirical analysis. Applied Economics Letters. 19(4), 345-348.

[5] Dergiades, T., 2014, Do investors' sentiment dynamics affect stock returns? Evidence from the US economy. Economics Letters 116(2012), 404-407.

[6] Diks, C., Panchenko, V., 2006. A new statistic and practical guidelines for nonparametric Granger causality testing. Journal of Economic Dynamics and Control 30(9-10), 1647-1669.

[7] Fama, E. F., French, K. R., 1995. Size and book-to-market factors in earnings and returns. Journal of Finance 50, 131-155.

[8] Granger, C., 1969, Investigating causal relations by econometric models and cross-spectral methods, Econometrica 37, 424-438.

[9] Lux, T., 2011. Sentiment dynamics and stock returns: the case of the German stock market. Empirical Economics 41 (3), 663-679.

[10] Rashid, A., 2007. Stock prices and trading volume: An assessment for linear and nonlinear Granger causality. Journal of Asian Economics 18(4), 595-612.

[11] Shefrin H., 2000. Behavioralizing finance. Foundations and Trends in Finance 4(1-2), 1-84

[12] Shiller R., 2000. Irrational Exuberance. Princeton U. Press, 2000

[13] Stambaugh, R. F., Yu, J., Yuan, Y., 2014, The long of it: Odds that investor sentiment spuriously predicts anomaly returns. Journal of Financial Economics, In Press.

[14] Statman, M., 2014, Behavioral finance: Finance with normal people. Borsa Istanbul Review 14(2), 65-73.

[15] Stelios, D., Bekiros, 2013. Irrational fads, short-term memory emulation, and asset predictability. Review of Financial Economics 22, 213-219. 